\title{
Rumah Sakit JiWa Dengan Konsep HeaLING ENVIRONMENT DI KOTA SEMARANG
}

\author{
Della Ratamanjari, Hadi Setyawan, Leny Pramesti \\ Program Studi Arsitektur \\ Jurusan Arsitektur Fakultas Teknik \\ Universitas Sebelas Maret Surakarta \\ Email : dellaratamanjari@gmail.com
}

\begin{abstract}
Designing Psychiatric Hospital in Semarang City is motivated by the imbalance between the capacity of the number of psychiatric hospital beds compared to the number of cases of mental illness visits in one year in the city, the lack of adequate mental hospital that already exists, and the problems that arise from the lack of effectiveness of the healing process in conventional mental hospital. The purpose of this issue is to obtain a mental hospital design that can address the needs of all people with mental disorders all around ex-residentie of Semarang and support the healing process of patients with mental disorders. The design problem is: how to apply architectural elements that can provide a positive influence on the psychological aspects of building users. The method used is based on the concept of healing environments. The result obtained is a psychiatric hospital that makes architectural elements as a part of the healing process.
\end{abstract}

Keywords: Psychiatric hospital, healing environment.

\section{PENDAHULUAN}

Profil Kesehatan Provinsi Jawa Tengah tahun 2011 menunjukkan angka ketidakseimbangan yang sangat signifikan antara kapasitas rumah sakit jiwa yang ada dengan kasus gangguan jiwa yang terjadi di Jawa Tengah, terutama Kota Semarang. Ketidakseimbangan tersebut tentunya berbuntut pada kurang efektifnya pelayanan kesehatan jiwa yang dapat diberikan oleh institusi terkait kepada masyarakat yang menjadi sasarannya. Kondisi pelayanan kesehatan jiwa yang ada saat ini pun kurang ideal bagi penyembuhan pasien dengan gangguan jiwa.

Pernyataan tersebut didukung oleh Ulrich dalam Dijkstra (2009), yang menyebutkan bahwa kebanyakan fasilitas pelayanan kesehatan jiwa dibangun dengan menekankan pada aspek fungsionalnya saja. Rumah sakit jiwa pun menjadi identik dengan berbagai situasi ketidaknyamanan fisik seperti suasana yang institusional, serba putih, kurangnya dekorasi dan dengan penataan yang sesederhana mungkin. Menurut Mason, Sachar, Fishman, Hamburg, Handlon dan Pride dalam Dijkstra
(2009), situasi semacam ini biasanya diikuti dengan rasa takut, kecemasan, perasaan tertekan dan ketidakpastian yang muncul dalam diri pasien. Hal ini tentunya dapat mengganggu jalannya proses penyembuhan pasien jiwa.

Di dalam kedokteran muncul Evidence-Based Care (EBC) yang merupakan upaya untuk memfokuskan pelayanan kesehatan pada peningkatan kualitas dan keamanan. Menurut Kobus dkk (2008), gagasan EBC berpengaruh pula pada desain fasilitas pelayanan kesehatan. Muncullah tren di mana arsitek dituntut untuk menyediakan bukti-bukti empiris bersamaan dengan rancangannya, apakah rancangan tersebut berkontribusi dalam peningkatan kualitas perawatan pasien atau tidak (Evidence-Based Design). Salah satu konsep yang kontribusi dalam peningkatan kualitas perawatan pasien dan mengedepankan bukti-bukti empiris dalam proses perancangannya ialah healing environment. 


\section{METODE}

\subsection{BRIEF ISSUED}

Menerangkan secara singkat isu yang melatarbelakangi pemilihan objek desain.

\subsection{DESIGN SITUATION EXPLORED}

Tahap ini bertujuan untuk memahami situasi desain dengan mengumpulkan sebanyak mungkin informasi yang dapat membantu pemecahan permasalahan.

Dalam hal ini, eksplorasi dilakukan dengan empat langkah:

1. Literature Searching

Melakukan eksplorasi melalui berbagai literatur.

2. Interviewing Users

Melakukan wawancara terhadap pengguna bangunan serupa dan pihak yang terkait dengan objek desain.

3. Investigating User Behavior

Melakukan pengamatan terhadap pola perilaku pengguna bangunan rumah sakit jiwa yang sudah ada.

4. Visual Inconsistency

Melakukan pengamatan terhadap objek yang sudah ada, untuk menemukan di bagian mana sebuah rumah sakit jiwa memerlukan perbaikan atau peningkatan.

\subsection{PROBLEM STRUCTURE PERCEIVED / TRANSFORMED}

Mengubah tujuan yang bersifat samarsamar menjadi kriteria yang dapat diraba dan diukur untuk lebih memahami hasil akhir desain yang ingin dicapai.

\subsection{FINAL DESIGN}

Untuk mendapatkan desain akhir yang diinginkan, digunakan metode CASA (Collaborative Strategy for Adaptable Architecture). Dengan menggunakan outline:

1. Sistem Desain dan Konstruksi

a. Menentukan kriteria tiap area desain, meliputi: ruang interior, bentuk eksternal, stabilitas struktural, servis, insulasi dan tapak.

b. Mengidentifikasi alternatif keputusan yang diambil tiap area desain.

c. Mengambil keputusan desain untuk tiap-tiap area desain.

2. Generasi Pertama Sub-sistem Desain dan Konstruksi
1) Mengidentifikasi kriteria yang menjadi tujuan.

2) Mengidentifikasi alternatif desain

3) Mengambil keputusan desain, diulang dengan melibatkan lebih banyak detail dari tiap-tiap area desain.

\section{ANALISIS}

\subsection{Analisis Peruangan}

Tabel 1. Kebutuhan Ruang

\begin{tabular}{|c|c|c|}
\hline PELAKU & KEGIATAN & $\begin{array}{l}\text { KEBUTUHAN } \\
\text { RUANG }\end{array}$ \\
\hline \multirow[t]{8}{*}{ Pasien } & Datang & Hall penerima \\
\hline & Administrasi & Ruang administrasi \\
\hline & $\begin{array}{l}\text { Pelayanan jiwa } \\
\text { dan non jiwa }\end{array}$ & Unit gawat darurat \\
\hline & & Unit rawat inap \\
\hline & & Unit rawat jalan \\
\hline & & Unit laboratorium \\
\hline & & Unit farmasi \\
\hline & & Unit rehabilitasi \\
\hline \multirow[t]{3}{*}{ Pembesuk } & Datang & Hall penerima \\
\hline & Menginap & Asrama keluarga \\
\hline & Membesuk & R.besuk keluarga \\
\hline \multirow{3}{*}{$\begin{array}{l}\text { Tamu/kunjun } \\
\text { gan }\end{array}$} & Datang & Hall penerima \\
\hline & $\begin{array}{l}\text { Menghadiri } \\
\text { acara }\end{array}$ & Exhibition hall \\
\hline & $\begin{array}{l}\text { Menghadiri } \\
\text { seminar }\end{array}$ & Auditorium \\
\hline \multirow[t]{4}{*}{ Pengelola } & Datang & Hall pengelola \\
\hline & Menerima tamu & R.tamu \\
\hline & Pertemuan/rapat & R.rapat \\
\hline & Pengelolaan & R.kerja \\
\hline \multirow[t]{12}{*}{ Karyawan } & Datang, absensi & R.kepegawaian \\
\hline & Ganti pakaian & R.ganti dan locker \\
\hline & Pelayanan jiwa & Unit laboratorium \\
\hline & & Unit farmasi \\
\hline & & Unit rawat jalan \\
\hline & & Unit gawat darurat \\
\hline & & Unit rawat inap \\
\hline & & Unit rehabilitasi \\
\hline & $\begin{array}{l}\text { Pendidikan dan } \\
\text { pelatihan }\end{array}$ & R. kelas \\
\hline & & R. seminar \\
\hline & & Perpustakaan \\
\hline & Menginap & Asrama \\
\hline \multirow[t]{10}{*}{ Servis } & Datang, absensi & R.kepegawaian \\
\hline & Ganti pakaian & R.ganti dan loker \\
\hline & Bekerja & Unit jenazah \\
\hline & & Unit kebersihan \\
\hline & & Unit pergudangan \\
\hline & & Unit keamanan \\
\hline & & Unit ME \\
\hline & & Unit CSSD \\
\hline & & Unit dapur \\
\hline & & Unit laundry \\
\hline
\end{tabular}




\subsection{Analisis Lokasi}

Pemilihan lokasi dapat mempengaruhi kualitas pelayanan kesehatan jiwa. Lokasi rumah sakit jiwa yang ideal telah diatur oleh Departemen Kesehatan RI.

1. Tujuan: Mendapatkan lokasi rumah sakit jiwa di pusat kota sesuai dengan Peraturan Menteri Kesehatan RI No.1993/Kdj/U/1970.

2. Dasar pertimbangan: Berada di wilayah pusat pelayanan kota dalam RTRW Kota Semarang tahun 20112031. Bukan termasuk daerah rawan bencana. Mudah diakses/dilalui jalur arteri kota. Dekat dengan fasilitas pendidikan tenaga medis.

\subsection{Analisis Pencapaian}

Pencapaian ke dalam bangunan harus mudah diakses namun tetap terjaga keamanannya di setiap titik.

1. Tujuan: menentukan main entrance, service entrance dan emergency entrance.

2. Dasar pertimbangan: Kemudahan akses, sirkulasi tapak yang aksesibel, arus kendaraan dan potensi jalan, tingkat keamanan.

3. Proses analisis:

Main Entrance (ME)

Mudah dijangkau dan terlihat dengan jelas. Menghadap langsung ke arah jalan utama. Meminimalkan titik untuk memperkecil kemungkinan pasien melarikan diri melalui jalur entrance.

Service Entrance (SE)

Diperuntukkan bagi karyawan, pengelola dan keperluan pergudangan.

Emergency Entrance (EE)

Diperuntukkan bagi kondisi darurat misalnya untuk akses masuk mobil pemadam kebakaran.

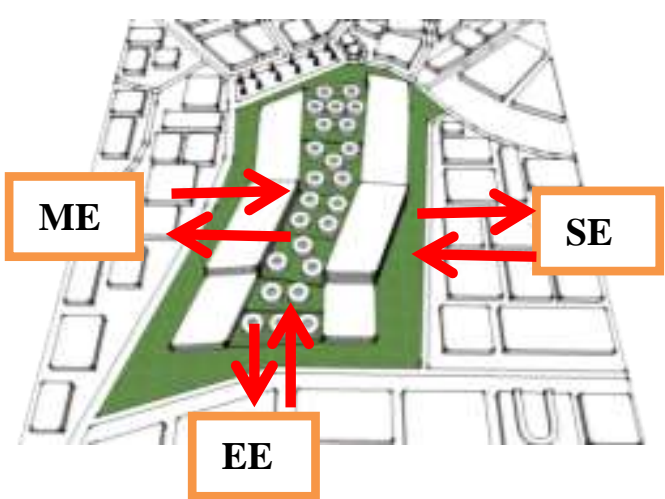

Gambar 1. Pola Pencapaian

\subsection{Analisis Pemintakatan}

Pemintakatan bertujuan agar tidak ada kegiatan yang saling menganggu dalam pelaksanaannya, sekaligus meningkatkan keamanan terutama bagi pasien rawat inap.

1. Tujuan: Menentukan mintakat (zoning) berdasarkan jenis kelompok kegiatan dan siapa saja yang boleh mengakses area tersebut.

2. Dasar pertimbangan: Analisis peruangan, analisis pencapaian, alur sirkulasi.

3. Proses analisis:

Kegiatan dikelompokkan berdasarkan kesamaan sifatnya, dihubungkan dengan alur sirkulasi yang dibedakan berdasarkan subjek yang mengakses kelompok kegiatan tersebut.

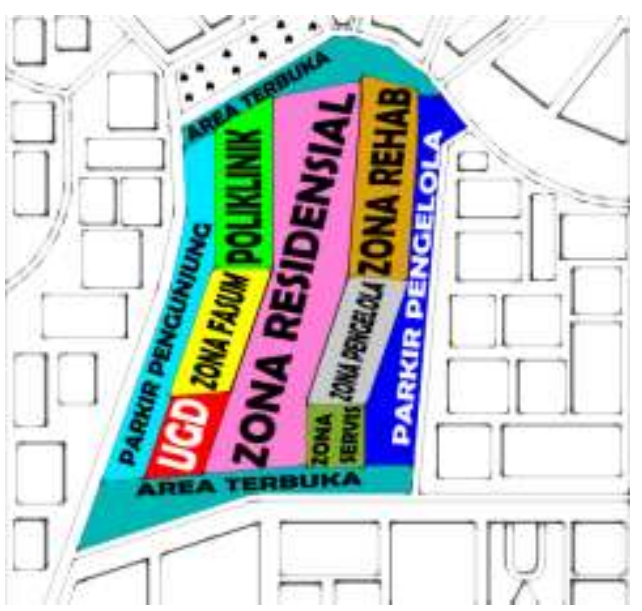

Gambar 2. Pola Pemintakatan Horizontal 


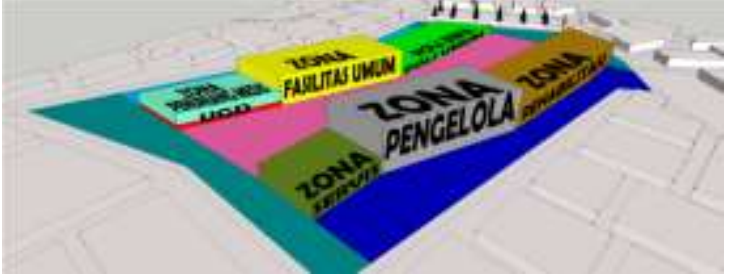

Gambar 3. Pola Pemintakatan Vertikal

\subsection{Analisis Bentuk Massa Dasar}

1. Tujuan: menentukan bentuk dasar yang bangunan yang dapat terkesan homey tanpa meninggalkan unsur formalnya.

2. Dasar pertimbangan: efisien lahan dan efektif mewadahi pelayanan medis.

3. Proses analisis:

Segiempat bersifat efektif dan efisien dalam penataan layout, digunakan pada bangunan fungsional (pelayanan medis).

Lingkaran bersifat dinamis dengan jarak pandang yang luas, digunakan pada unit rawat inap.

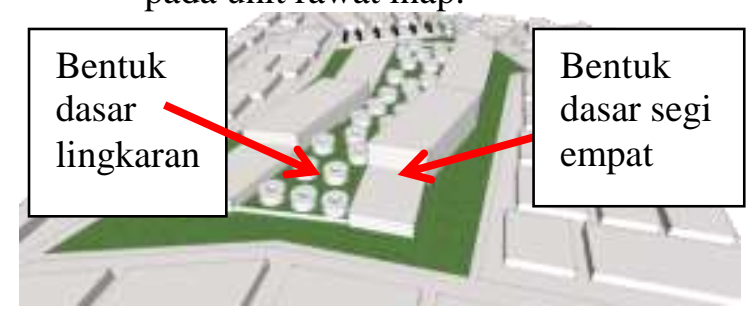

Gambar 4. Bentuk Massa Dasar

\subsection{Analisa Pola Tata Massa}

1. Tujuan: Menentukan penataan massa bangunan yang mendukung keamanan rumah sakit jiwa tanpa melupakan peranannya sebagai healing environment, di mana bangunan harus terkesan homey tanpa kesan memenjarakan.

2. Dasar pertimbangan:

Mudah pencapaian, mudah sirkulasi, mudah pengawasan, memperkecil blind spot.

3. Proses analisis:

Digunakan kombinasi dua sistem komposisi. Bangunan fungsional ditata secara linier seolah memagari area bangunan unit rawat inap yang ditata secara cluster di tengah tapak. Posisi pemagaran ini memungkinkan bangunan fungsional mengawasi area unit rawat inap secara menyeluruh.

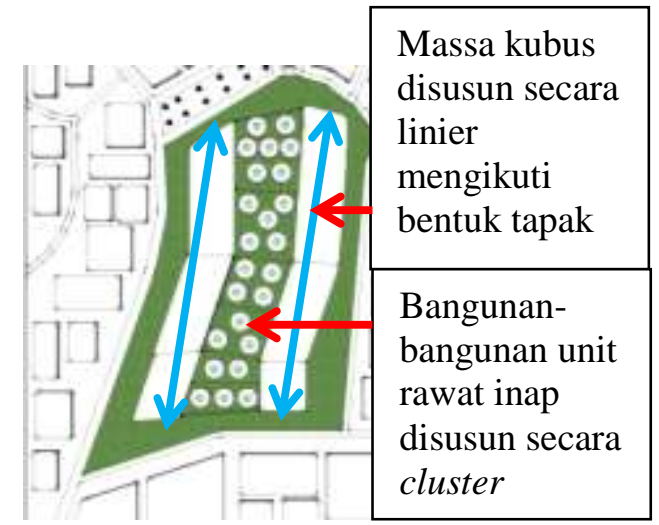

Gambar 5. Pola Tata Massa

\subsection{Analisis Gubahan Massa}

1. Tujuan: Menentukan gubahan massa yang dapat memberikan gambaran kepada masyarakat mengenai fungsi dan sifat kegiatan bangunan rumah sakit jiwa yang formal, higienis namun tetap terkesan ramah.

2. Dasar pertimbangan: Penerapan metode non-tradisional, yakni membawa stimulus positif lingkungan rural ke lingkungan kota. Penerapan LED-embedded glass untuk terapi cahaya.

3. Proses analisis:

Bangunan mempertahankan bentuk dasarnya dengan permukaan yang datar dengan luasan lebar agar $L E D$ embedded glass dapat dengan mudah membentuk berbagai efek gradasi warna, tulisan maupun motif tertentu pada fasad. Selain sebagai sarana terapi cahaya, ia juga dapat menjadi elemen estetika pada fasad.

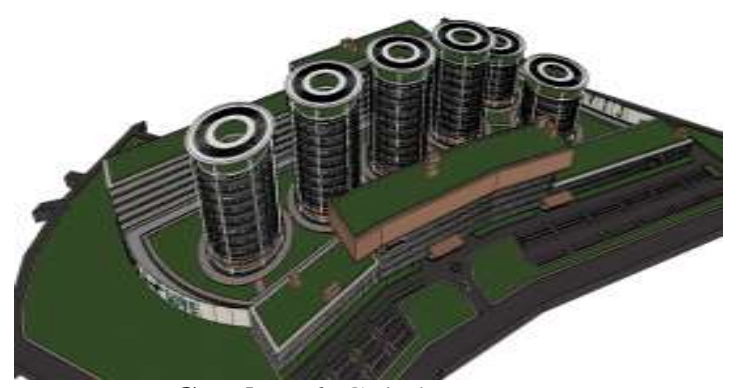

Gambar 6. Gubahan Massa

\subsection{Analisa Karakteristik Konsep Healing Environment}

\subsubsection{Setting Interior}

Kriteria: homey, menggunakan aksentuasi warna dan gambar. 
Aplikasi desain: suasana di dalam rumah tinggal diimplementasikan ke dalam ruang interior rumah sakit jiwa.

Tabel 2.Ruang di Rumah Tinggal dan Implementasinya dalam Rumah Sakit Jiwa

\begin{tabular}{|l|l|}
\hline RUANG & IMPLEMENTASI \\
\hline Teras rumah & Ruang duduk \\
\hline Ruang tamu & Ruang tunggu \\
\hline Kamar tidur & Bangsal pasien \\
\hline Kamar mandi & Kamar mandi pasien \\
\hline Ruang makan & Ruang makan pasien \\
\hline Halaman rumah & $\begin{array}{l}\text { Vertical garden, zen } \\
\text { garden, indoor } \\
\text { garden }\end{array}$ \\
\hline
\end{tabular}

\subsubsection{Pencahayaan dan Bukaan}

Kriteria: Memaksimalkan pencahayaan alami, dapat diatur intensitasnya sesuai keinginan pengguna. Membatasi jumlah jendela yang dapat dibuka. Memberikan akses penghawaan alami untuk pasien.

Aplikasi desain:

Menggunakan Intelligent Dynamic Daylighting System (Polycarbonate Glazing Panel untuk penutup jendela.

Menggunakan jendela kisi-kisi pada bangsal pasien dengan perletakan inlet dan outlet atas-bawah.

Menggunakan skylight sebagai penutup atap.

\subsubsection{Furniture}

Kriteria: Tidak mudah rusak, tahan benturan, tidak berujung tajam, sulit dipindah agar tidak diangkat untuk dijadikan senjata, tidak dapat digunakan sebagai pengait atau pijakan.

Aplikasi desain:

Material utama berupa kayu atau plastik. Bahan kayu menggunakan kayu lapis vinyl. Kain pelapis menggunakan fabric vinyl.

Setiap sudut furniture ditumpulkan.

Seluruh kompartemen tidak dapat dikunci untuk mencegah pasien menyembunyikan benda berbahaya. Kaca/cermin digantikan dengan polycarbonate reflective.

Segala street furniture terpatri pada tempatnya.

\subsubsection{Hiasan / Elemen estetika}

Kriteria: karya seni menggambarkan objek realistis, tidak berupa gambar abstrak/ambigu dan yang memiliki efek relaksasi.

Aplikasi desain: Karya seni yang dipilih berupa lukisan alam dan kutipan kalimat motivasi/pesan positif.

Karya seni berupa lukisan alam diletakkan pada area di mana pasien menghabiskan banyak waktunya, namun memiliki jangkauan view yang terbatas.

\subsubsection{Koridor}

Kriteria: Menghindari koridor terlalu panjang. Dilakukan pertimbangan terhadap kebutuhan untuk mengurangi stres pasien maupun staf.

Aplikasi desain: Untuk mensiasati koridor agar tidak terlihat terlalu panjang, digunakan trik warna dan ornamen.

Disediakan ceruk yang dapat digunakan untuk berdiskusi atau beristirahat saat tengah melintasi koridor. Di dalam ceruk dilengkapi dengan meja misalnya untuk meletakkan yang akan didiskusikan dan lukisan alam untuk memberikan efek relaksasi walaupun sedang berada di koridor.

\subsubsection{Material Penyusun Interior}

Kriteria: Menghindari penggunaan material buatan, pola-pola kompleks, warna yang terlalu tajam, susunan warna monokrom dan permukaan yang memantulkan bayangan. Area sirkulasi tidak tertutup karpet. Memilih pelitur/pelapis yang sesuai jenis kegiatan.

Aplikasi desain: Material dipilih berdasarkan makna asosiasinya oleh pasien. Kejamakan jenis material yang hadir dalam eksterior maupun interior bangunan dapat membantu pasien mengaktifkan indera dan persepsinya.

Tabel 3.Unsur material dan makna asosiasinya

\begin{tabular}{|l|l|}
\hline MATERIAL & MAKNA ASOSIASI \\
\hline Tanah & Dukungan \\
\hline Langit & Keterbukaan \\
\hline Tanaman hijau & Kelahiran baru \\
\hline
\end{tabular}




\begin{tabular}{|l|l|}
\hline Batu & Kehalusan \\
\hline Air & Refleksi, relaksasi \\
\hline Pasir & Ketenangan \\
\hline Kayu & Kehangatan \\
\hline Baja & Kekuatan \\
\hline Kaca & Cahaya \\
\hline
\end{tabular}

Sumber: Schaller (2012)

\subsubsection{Warna}

Kriteria: Penggunaan warna yang tepat, sesuai dengan efek psikologis yang ingin ditimbulkan pada pasien saat berada di ruangan tersebut Aplikasi desain:

Terdapat dua tema warna yang memiliki efek psikologis yang berbeda. Penggunaan tema tertentu menyesuaikan dengan jenis kegiatan yang berlangsung di ruangan tersebut.

Tabel 4. Tema Warna dan Penerapannya

\begin{tabular}{|l|l|}
\hline TEMA 1 & TEMA 2 \\
\hline Warna: & Warna: \\
Krem & Kuning keemasan \\
Coklat & Biru turquoise \\
Coklat muda & Kuning labu \\
\hline Manfaat: & Hijau rumput \\
Relaksasi & Manfaat: \\
Mengurangi & Aktif \\
ketegangan & Sadar \\
\hline Cocok diterapkan di: & Tenang \\
Zona rawat jalan & Korok diterapkan di: \\
Zona residensial & Fasad \\
(kamar pasien dan & Zona fasilitas umum \\
kamar mandi pasien) & Zona residensial \\
Zona rehabilitasi & (ruang sosial: ruang \\
Zona penunjang & duduk-duduk dan \\
medis & ruang makan) \\
& Zona pengelola \\
& Zona servis \\
\hline
\end{tabular}

Sumber: Putri dkk (2011)

\subsection{Analisa Struktur}

Tujuan: Menentukan sistem struktur yang dapat mewadahi bangunan dengan konsep healing environment.

Dasar Pertimbangan: Rumah sakit jiwa yang direncanakan terdiri atas massa jamak, memiliki ketinggian maksimal \pm 9 lantai. Perlunya memperhatikan keamanan pengguna.
Proses analisis:

1. Sub structure

Jenis pondasi memperhatikan kondisi tanah di Semarang dan mampu menahan struktur bangunan high-rise. Pondasi yang paling tepat menggunakan pondasi tiang pancang.

2. Supper structure

Jenis struktur badan bangunan harus memfasilitasi kemungkinan pengembangan di masa yang akan datang (struktur bangunan tumbuh). Struktur badan bangunan yang paling efisien menggunakan rigid frame.

3. Upper structure

Jenis penutup atap yang mendukung pencahayaan alami. Atap skylight menggunakan bahan tembus cahaya sehingga dapat mengoptimalkan masuknya cahaya matahari, serta nampak estetis. Bahan tembus cahaya tersebut dapat menggunakan polycarbonate glazing panel agar dapat diatur intensitas cahayanya.

\section{KESIMPULAN (KONSEP DESAIN)}

Dari hasil analisa serta hasil korelasi dari beberapa data di atas, maka diperoleh hasil berupa desain Rumah Sakit Jiwa di Kota Semarang sebagai berikut.

Nama : Rumah Sakit Jiwa Semarang
Lokasi
: Jl. Sultan Agung,

Kecamatan Candisari, Semarang.

$\begin{array}{ll}\text { Luas Lahan } & : 79.913 \mathrm{~m}^{2} \\ \text { Luas Bangunan } & : 47.903,67 \mathrm{~m}^{2} \\ \text { Kapasitas TT } & : 600 \mathrm{TT}\end{array}$

Kapasitas pengguna : 2352 orang

Kegiatan : Pelayanan kesehatan jiwa terpadu

Penerapan healing environment pada rumah sakit jiwa agar dapat mendukung proses penyembuhan pasien gangguan jiwa, terletak pada beberapa hal:

1. Pemilihan tapak di daerah pusat pelayanan utama kota.

2. Menyediakan ruang yang memadai untuk keperluan keluarga pasien.

3. Menyediakan ruang untuk mendukung kesejahteraan karyawan.

4. Menyediakan ceruk komunikasi pada koridor. 
5. Mengurangi blind spot melalui penataan massa bangunan.

6. Membentuk taman kompak yang kaya akan unsur vegetasi, air, dan bebatuan pada zona residensial (zona rawat inap).

7. Menyerukan slogan positif kepada masyarakat untuk menepis stigma negatif rumah sakit jiwa.

8. Mengutamakan interior sebagai unsur pembangkitkan ketajaman indera dan persepsi yang paling dekat dengan pasien melalui perpaduan unsur-unsur material dan asosiasinya.

9. Meredesain zen garden agar aman bagi pasien gangguan jiwa.

10. Meredesain dinding pengaman agar tidak tampak memenjarakan.

11. Memastikan tidak adanya objek dalam jangkauan pasien yang berpotensi membahayakan pasien.

12. Menggunakan LED-embedded glass dalam setiap lapisan polycarbonate yang melapisi fasad bangunan sebagai terapi cahaya.

\section{REFERENSI}

Dijkstra, Karin. 2009. Understanding Healing Environments : Effects of Physical Environmental Stimuli on Patients' Health and Well-being. Thesis. University of Twente. Faculty of Science and Technology. Enschede.

Kobus, Richard L., Michael Bobrow, Julia Thomas, Thomas M. Payette dan ShoPing Chin. 2008. Building Type Basics for Healthcare Facilities. New Jersey: John Wiley \& Sons Inc.

Schaller, Brian. 2012. Architectural Healing Environments. Thesis. Syracuse University. Department of Architecture. New York.

Putri, Debri Haryndia., Widiharjo, Wibisono, Andriyanto. 2011. Relasi Penerapan Elemen Interior Healing Environment Pada Ruang Rawat Inap dalam
Mereduksi Stress Psikis Pasien (Studi Kasus: RSUD. Kanjuruhan, Kabupaten Malang). Bandung : LPPM ITB, ISSN: 1978-3078. 


\section{LAMPIRAN}

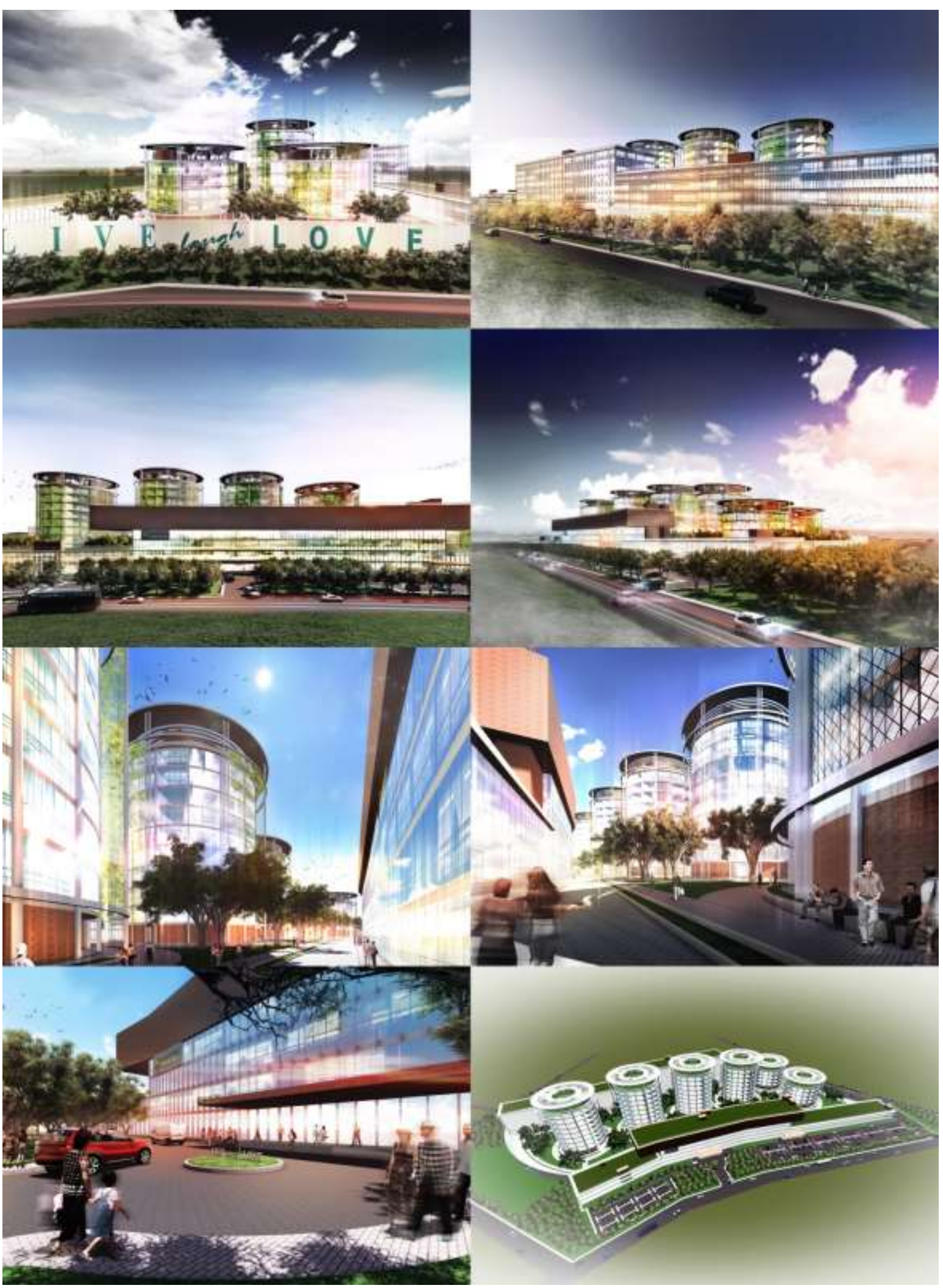

Lampiran 1. Perspektif Eksterior 


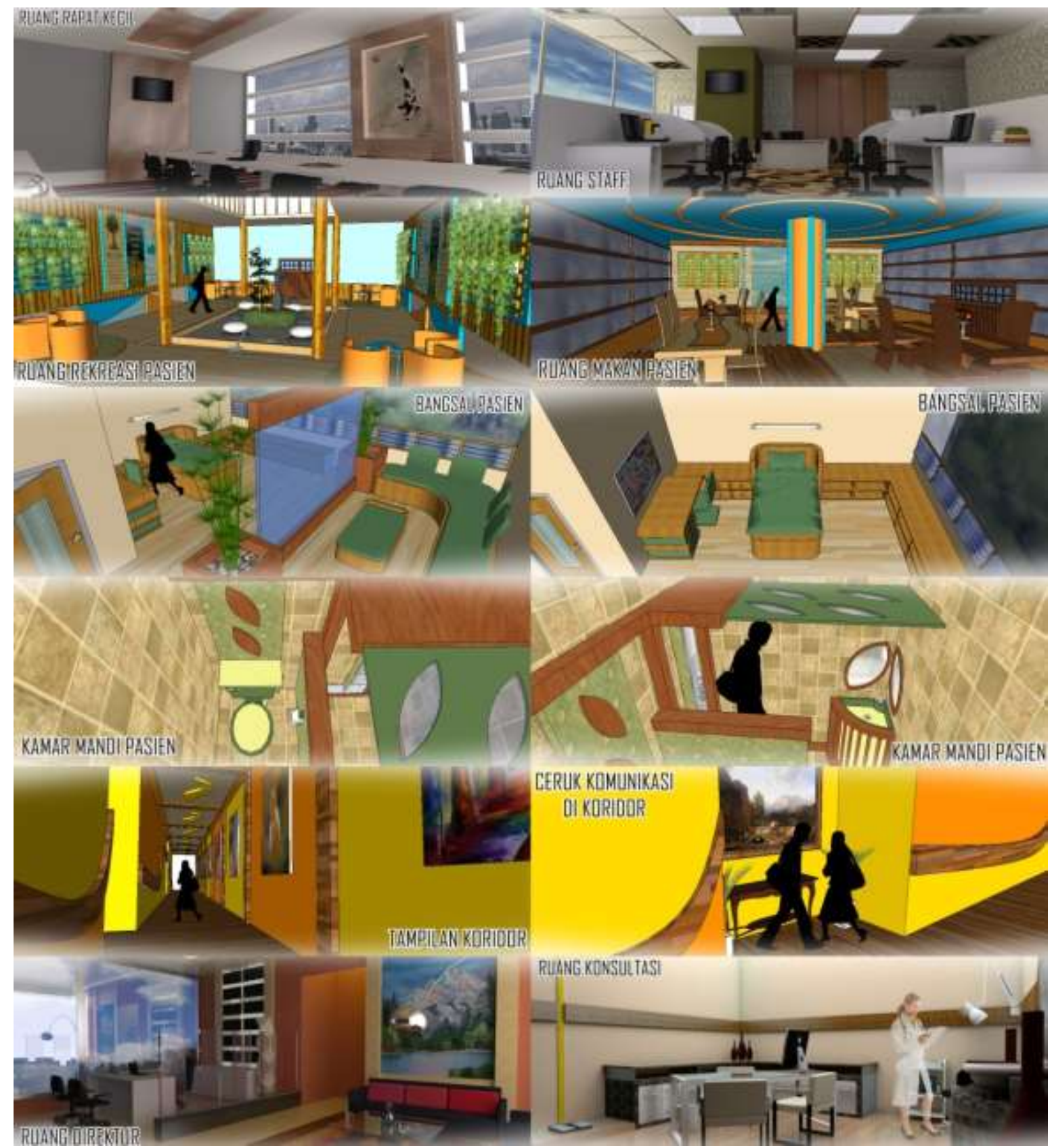

Lampiran 2. Perspektif Interior 


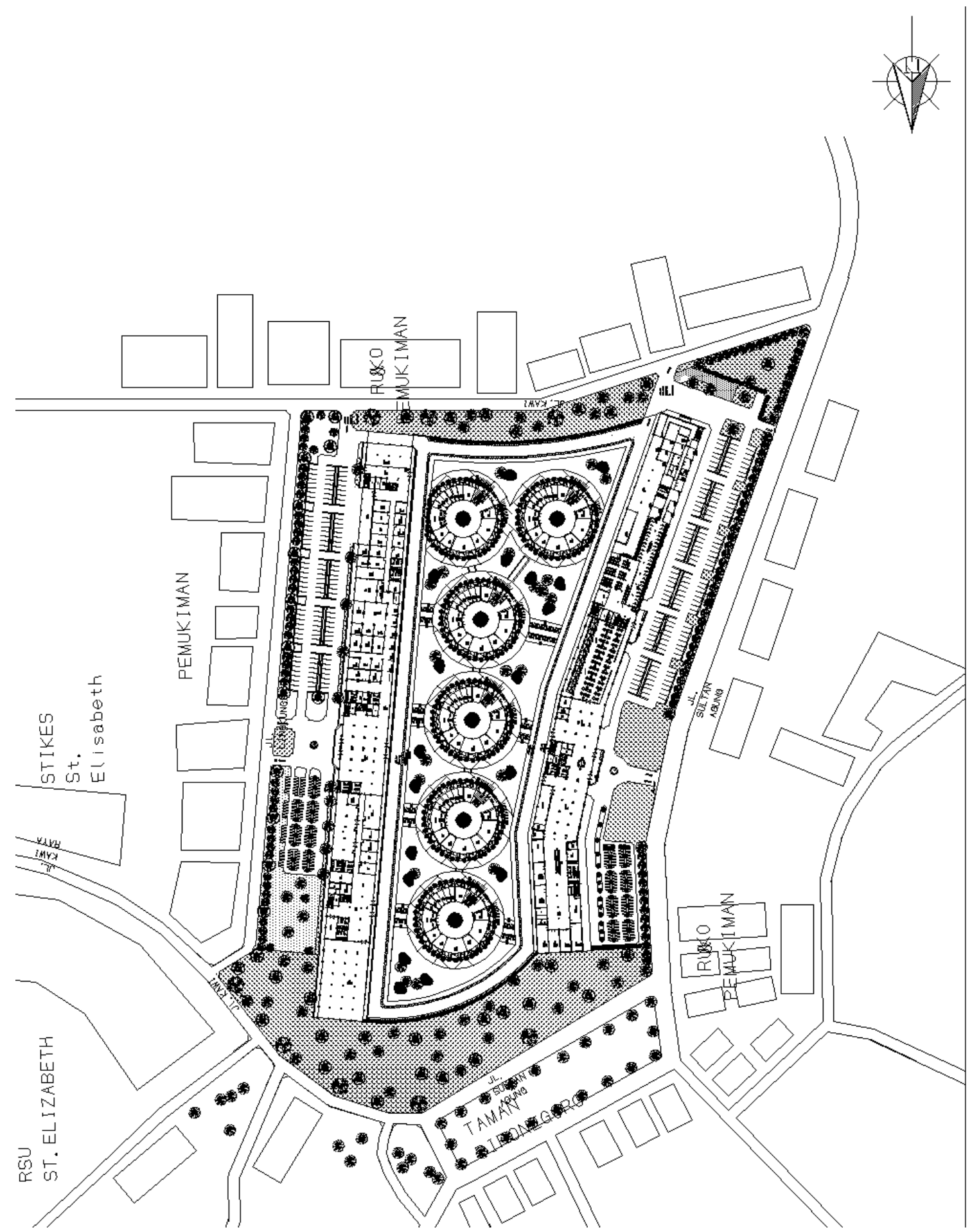

Lampiran 3. Rencana Tapak 